Families and Work Institute. Access: www.

familiesandwork.org/.

The Families and Work Institute (FWI) is a research center providing data on the social changes affecting the U.S. workforce. Established in 1989, FWI identifies emerging trends and issues with the goal of "shaping the language of debates to move the discussion forward." FWI has addressed subjects such as child care and balancing work and family and is currently exploring the benefits of flexibility in the workplace.

FWI is not a clearinghouse or an online research library. Instead the FWI site presents information on studies conducted in conjunction with corporate funders and foundations. It has produced Highlights of the National Study of the Changing Workforce, which traces trends in the workplace over the last 25 years. This study covers topics such as the effect of technology on employees, changes in men and women's family life, and the growth of small independent-owned businesses. The research published by FWI is available for purchase from the Web site.

Another resource, which is free to site visitors, is the "Community Mobilization Forums" (CM Forum). It provides information and previously successful strategies, which individuals or groups may follow or adapt to enact change at the local level. Although not complete at review time, the CM Forum has valuable case studies to download.

FWI's target audience is employers, employees, parents, community advocates, and educators. Since the Web site is not a clearinghouse, it may be of limited interest for academic users. Students may submit questions to the FWI staff but are warned of a two-week response time.

They are encouraged, however, to consult their library resources and online databases before contacting FWI. Librarians with human

Joni R. Roberts is associate university librarian for public services and collection development at Willamette University, e-mail: jroberts@willamette. edu, and Carol A. Drost is associate university librarian for technical services at Willamette University, e-mail: cdrost@willamette.edu resources or management programs may find the publications welcome additions to their collections. Executive summaries of most of the research publications are available via the Web site.

It is difficult to determine the age of the site and frequency of updates; some pages are dated, while others are not. A menu is located on the left of every page within the site, making for easy navigation. The FWI site is clearly organized and simple to use. -Kimberly Bartosz, University of Wisconsin Parkside, bartosz@uwp.edu

PLANTS Database. Access: http://plants.usda. gov/.

PLANTS Database Web site is an innovative new resource developed by the National Plant Data Center (NPDC), a branch of the USDA's Natural Resources Conservation Service. PLANTS disseminates authoritative information about the vascular and nonvascular plants of the United States and its territories. Judged to be one of the top 50 innovative programs in federal government, PLANTS supports NPDC's mission to acquire, develop, improve, and disseminate plant data to support efforts to improve the ecological health of the United States.

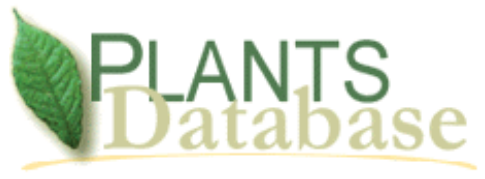

The homepage for the database is divided into several sections. "Plant topics" provides easy access to images, distribution information, fact sheets, and classification information for alternative crops, wetland plants, and plants that are culturally significant, threatened, endangered, invasive, or noxious. A link to the advanced query mode for the database can be accessed from this section of the homepage. "Plant tools" links to specialized databases, including the "Crop Nutrient Tool" for calculating crop yields and nutritional requirements and the "VegSpec" tool for determining site-specific adaptability of plant species. "Resources offsite" 
provides direct links to numerous national and global plant checklists. "PLANTS download" provides data files that can be downloaded into Excel or other spreadsheets; also included are the "Complete PLANTS checklist," the plants checklists for various states, a grazing and spatial analysis tool for the state lists, and U.S. Forest Service data.

A simple search of the PLANTS database, using either the common or scientific plant name, provides access to a profile for the specified plant. Each plant profile includes photographic images and a distribution map. Also included are links to information about related genera, information about the plant's endangered/threatened status, and many related Web sites. A simple search on Abies concolor also provides links to a plant dictionary, a gymnosperm database, a medicinal plants site, research on wood anatomy, and much more. Advanced searches can be qualified by core data specifications, such as distribution, taxonomy, life form, U.S. nativity, and legal status, as well as characteristics data including morphology/physiology, growth requirements, reproduction/propagation, and suitability/use.

PLANTS facilitates information exchange among various government agencies and is a valuable resource for librarians, students, botanists, ecologists, gardeners, farmers, ranchers, and environmental scientists.-Susan Case, University of Kansas, scase@ku.edu

\section{Center for Drug Evaluation and Research.}

Access: http://www.fda.gov/cder/index.html.

With the seemingly ever-increasing amount of drug advertising currently in the media, a tool with solid, factual information about drugs is needed.

The Center for Drug Evaluation Research (CDER) Web site is an easy-to-use, searchable source of drug information for both consumers and medical professionals. CDER is part of the U.S. Food and Drug Administration (FDA) and its mission is "to assure that safe and effective drugs are available to the American people." CDER's primary duties are to evaluate new drugs, approve clinical trials, carefully review drug manufacturers' research, and decide if a drug is approved for public use.

U.S. Food and Drug Administration CENTER FOR DRUG EVALUATION AND RESEARCH
One of the most useful parts of the site is "Drugs@FDA," a searchable database with official FDA information about generic, prescription, over-the-counter, and discontinued drugs. Users can browse or search by a drug's name or active ingredients. They can also do an advanced search by application number or approval dates. The database contains information, including strength, dosage form, status, manufacturing company, similar drugs, ingredients, and FDAapproved labeling. It also includes documents, in PDF format, about the drug's approval history, manufacturing, and packaging. There is a glossary and instructions for searching. "Drugs@FDA" contains information similar to the Physicians' Desk Reference.

"What's New @ CDER" lists FDA approvals, recalls, drug label revisions, and warnings. Users can subscribe to daily or weekly e-mail updates. The site has information on buying and using drugs, drug shortages, an inactive ingredient database, a post-marketing study commitments database, drug information sheets prepared by pharmacists, and the National Drug Code Directory. Users can search the Orange Book, also known as Approved Drug Products with Therapeutic Equivalence Evaluations, to find alternative medications with the same active ingredients. The Web site also contains information about hot topics, such as botanical drugs, bioterrorism, biological therapeutic products, and the drug approval process. It has information about CDER's offices, divisions, and current personnel, as well as its 90-year history.

The Web site can be confusing with sections, such as "Who We Are" and "What We Do," which supply links instead of the information itself. In addition, most documents are labeled with the date they were posted, but users must check carefully as the dates vary widely, and some documents are over ten years old. Some documents are also available in Spanish. The site search is powered by Google.

Overall, the site is user-friendly and contains valuable information about all human drugs. The CDER Web site is recommended for students, faculty, professionals, and consumers who need current information about generic, over-the-counter, or prescription drugs.-Kate Peterson, California State University, Long Beach, jpeters4@csulb.edu 